\title{
The sensitivity of the tropical circulation and Maritime Continent precipitation to climate model resolution
}

\author{
R. Schiemann • M.-E. Demory $\cdot$ M. S. Mizielinski • \\ M. J. Roberts • L. C. Shaffrey • J. Strachan • \\ P. L. Vidale
}

Received: 26 December 2012/Accepted: 6 November 2013/Published online: 5 December 2013

(C) The Author(s) 2013. This article is published with open access at Springerlink.com

\begin{abstract}
The dependence of the annual mean tropical precipitation on horizontal resolution is investigated in the atmospheric version of the Hadley Centre General Environment Model. Reducing the grid spacing from about 350 $\mathrm{km}$ to about $110 \mathrm{~km}$ improves the precipitation distribution in most of the tropics. In particular, characteristic dry biases over South and Southeast Asia including the Maritime Continent as well as wet biases over the western tropical oceans are reduced. The annual-mean precipitation bias is reduced by about one third over the Maritime Continent and the neighbouring ocean basins associated with it via the Walker circulation. Sensitivity experiments show that much of the improvement with resolution in the Maritime Continent region is due to the specification of better resolved surface boundary conditions (land fraction, soil and vegetation parameters) at the higher resolution. It is shown that in particular the formulation of the coastal tiling scheme may cause resolution sensitivity of the mean simulated climate. The improvement in the tropical mean precipitation in this region is not primarily associated with the better representation of orography at the higher resolution, nor with changes in the eddy transport of moisture. Sizeable sensitivity to changes in the surface fields may be one of the reasons for the large variation of the mean tropical precipitation distribution seen across climate models.
\end{abstract}

R. Schiemann $(\bowtie) \cdot$ M.-E. Demory · L. C. Shaffrey ·

J. Strachan · P. L. Vidale

NCAS-Climate, Department of Meteorology, University of Reading, Earley Gate, PO Box 243, Reading RG6 6BB, UK e-mail: r.k.schiemann@reading.ac.uk

M. S. Mizielinski · M. J. Roberts

Met Office Hadley Centre, FitzRoy Road, Exeter EX1 3PB, UK
Keywords Precipitation - Climate model bias . Resolution · GCM · Boundary conditions · Maritime Continent $\cdot$ Walker circulation $\cdot$ Coastal tiling

\section{Introduction}

It is widely held that scale interactions (between short/ small and long/large scales in time and space) are an important feature of the climate system, in particular in the tropics (e.g., Slingo et al. 2003, 2009). Consequently, a change in the resolution of a climate model may be expected to impact on the simulated climate, not only at the truncation scale but also at much larger scales. Indeed, systematic resolution dependencies have been described for a number of models and phenomena (e.g., Manabe et al. 1970; Boville 1991; Senior 1995; Williamson et al 1995; Stephenson et al. 1998; Pope and Stratton 2002). While it is well known that the increase of resolution is not a panacea for removing climate-model biases (e.g., Slingo et al. 2003), beneficial impacts have been documented in a range of more recent studies both for the atmosphere and the ocean. Roberts et al. (2004) show that increasing the ocean resolution in a coupled global circulation model to $1 / 3^{\circ}$ allows the ocean model to represent eddies and is associated with an improved mean ocean state. In the southeastern Pacific, the HiGEM model at $1 / 3^{\circ}$ oceanic resolution represents small-scale $(<450 \mathrm{~km})$ transient features and associated heat transports that agree better with available observations than in the coarser-resolution $\left(\sim 1^{\circ} \times 1^{\circ}\right)$ Hadley Centre General Environment Model (HadGEM1) (Toniazzo et al. 2009). At sufficient resolution in the atmosphere and the ocean, Roberts et al (2009) and Shaffrey et al (2009) find for the HiGEM model that small-scale interactions between the atmophere and 
instability waves in the tropical Pacific can be captured realistically improving the simulation of the mean state of the tropical Pacfic, the Walker circulation, and of all aspects of ENSO. Strachan et al (2012) report improvements in the number and geographical distribution of tropical cyclones in a series of atmosphere-only simulations with the HadGEM1 model; and Demory et al (2013) find, using the same model simulations, that the global water and energy cycles are represented more realistically at higher resolution.

Despite regular improvements, the representation of the (tropical) mean climate continues to be a challenge for state-of-the-art general circulation models (GCMs). Notably the tropical precipitation distribution has been difficult to simulate [e.g., Randall et al (2007), section 8.3.1.2, Martin et al (2010), Gent et al (2011)]. Characteristic precipitation biases occur in atmosphere-only simulations and may be exacerbated in coupled models (Hack et al. 2006). Precipitation is a key predictive variable from an environmental and socioeconomic point of view. Moreover, precipitation biases are an indicator of tropical heating errors and limit the confidence in GCMs in applications such as seasonal forecasting (e.g., Wang et al. 2007) or the identification of remote (tropical) forcing of events in the extratropics (e.g., Rodwell and Hoskins 1996). These biases are very pronounced over the Maritime Continent and the neighbouring ocean basins (Neale and Slingo 2003; Qian 2008). This is the region of largest precipitation and tropical heating, and the correct representation of its climate is crucial for both the tropical and extratropical mean state. For example, the ability of a model to capture atmospheric moisture transport and precipitation over the Maritime Continent is tightly linked to its ability to represent the zonal tropical overturning circulation, and may be a prerequisite for correctly simulating the present and future intensity and location of the Walker circulation (Held and Soden 2006; Vecchi et al. 2006).

In this study, we investigate the sensitivity of the tropical mean climate to horizontal resolution in a recent version of the Met Office Hadley Centre climate model. More specifically, we aim to characterize the changes in the mean tropical precipitation due to a decrease of the atmospheric grid spacing from about 350 to $110 \mathrm{~km}$, and to advance our understanding of why and how the model exhibits resolution dependence. We use a series of model experiments designed to this end; and focus on the Maritime Continent region where model resolution might be of particular relevance due to the complex arrangement of land and sea (Neale and Slingo 2003).

The outline of the paper is as follows. Section 2 describes the GCM used here, the setup of the model experiments, and observations and reanalysis data. In Sect. 3 , we give an overview of how the mean tropical climate depends on resolution and raise hypotheses of what may cause the resolution dependence. In Sect. 4, sensitivity experiments are described that assesses the dependence of the simulated climate on the resolution of surface boundary fields over the Maritime Continent. The paper is concluded in Sect. 5.

\section{Models, methods, and data}

The atmospheric version of the Hadley Centre General Environment Model (adGEM1; Johns et al. 2006) is used at different horizontal resolutions (N48-N216; see Table 1) and otherwise very similar model formulation. The model configurations at N48 and N96 resolution have a time step of $30 \mathrm{~min}$ and are the same as in Strachan et al (2012).

The N144 model was built for this study. It uses the HadGAM1 model formulation and the same surface boundary condition data as the atmospheric part of the High-resolution General Environmental Model [HiGEM; Shaffrey et al (2009)]. The time step for this model is 20 min. Small adjustments (of the settings in the N48 and N96 model) are made to the dynamics of this model, including the vertical velocity threshold for targeted diffusion and polar filtering, to permit it to run multi-decadal climate simulations. Our sensitivity studies indicate that these adjustments have minimal impact on the simulated climate compared to the impact of resolution changes. It should also be noted that, for historical reasons, the land fraction in the N144 model is based on a slightly different dataset than in the N48 and N96 models. ${ }^{1}$ This is reflected in a somewhat higher land fraction in the N144 model (Table 2).

We have also conducted sensitivity experiments with the N96 and N144 models where we regionally replace the original (N96 or N144) surface boundary fields with coarse (N48) surface data. These experiments are described in detail in Sect. 4.

In addition to the simulations at N48-N144 resolutions, simulations at N216 resolution and with a time step of $15 \mathrm{~min}$ are available. These are based on a model configuration that is still similar to the N48-N144 models, yet some more modifications were necessary to ensure model stability at the even higher resolution. These modifications include the reduction of the Convective Available Potential Energy (CAPE) timescale from $60 \mathrm{~min}$ at N48-N144 to 30 min at N216, enabling horizontal diffusion, and a

\footnotetext{
${ }^{1}$ It is the same as that in the atmospheric part of the HiGEM (Shaffrey et al. 2009) model. The ocean in HiGEM has $1 / 3^{\circ}$ resolution, and the atmospheric land-fraction and land-sea mask in that model were constructed to be consistent with the $1 / 3^{\circ}$ ocean land-sea mask. In the N48 and N96 models, these fields were derived to be consistent with the $1^{\circ}$ land-sea mask of the ocean model.
} 
Table 1 Model experiments, observations, and reanalysis data

\begin{tabular}{llllllll}
\hline Name & Resol. & Lon. & Lat. & $\Delta x($ eq. $)$ & $\Delta y$ & $\Delta t$ & References \\
\hline HadGAM1-N48 & $\mathrm{N} 48$ & $3.75^{\circ}$ & $2.5^{\circ}$ & 417 & 278 & 30 & Johns et al. (2006), Martin et al. (2006), \\
HadGAM1 & $\mathrm{N} 96$ & $1.88^{\circ}$ & $1.25^{\circ}$ & 208 & 139 & 30 & Ringer et al. (2006) \\
HadGAM1-N144 & $\mathrm{N} 144$ & $1.25^{\circ}$ & $0.83^{\circ}$ & 139 & 93 & 20 & \\
HadGAM1-N216 & $\mathrm{N} 216$ & $0.83^{\circ}$ & $0.56^{\circ}$ & 93 & 62 & 15 & \\
GPCP-21 & - & $\left(2.5^{\circ}\right)$ & $\left(2.5^{\circ}\right)$ & $(278)$ & $(278)$ & - & Adler et al. (2003), Huffman et al. (2009) \\
CRUTEM3 & - & $\left(5^{\circ}\right)$ & $\left(5^{\circ}\right)$ & $(556)$ & $(556)$ & - & Brohan et al. (2006) \\
HadSST2 & - & $\left(5^{\circ}\right)$ & $\left(5^{\circ}\right)$ & $(556)$ & $(556)$ & - & Rayner et al. (2006) \\
ERA-Interim & $\mathrm{T} 255$ & - & - & 79 & 79 & - & Dee et al. (2011) \\
\hline
\end{tabular}

The columns show the name, resolution, grid spacings (in degrees longitude, latitude, and in $\mathrm{km}$ at the equator), the time step in minutes, and references. Numbers in parenthesis refer to the spatial grid on which interpolated observational datasets are made available

Table 2 Land fraction (\%) at different resolutions, averaged over the whole globe and over the Maritime Continent $\left(95.625-140.625^{\circ} \mathrm{E}\right.$, -8.75 to $3.75^{\circ} \mathrm{N}$ )

\begin{tabular}{llll}
\hline & $\mathrm{N} 48$ & $\mathrm{~N} 96$ & $\mathrm{~N} 144$ \\
\hline Global & 28.7 & 28.7 & 29.7 \\
Maritime Continent & 26.7 & 26.4 & 31.2 \\
\hline
\end{tabular}

reduction of the autoconversion parameter. Our sensitivity experiments show that the impact of these modifications on the simulated climate might not be negligible. We therefore briefly include a result of the N216 model in Sect. 3, but our conclusions regarding the resolution-dependence of the HadGAM1 model climate are based on the N48-N144 models.

We analyse AMIPII-style [Atmospheric Model Intercomparison Project; Taylor et al (2000)] simulations covering the period 1979-2002. Three such simulations, i.e. ensemble members, generated by perturbing the least significant bit of the numerical values of the initial potential temperature field, are available for the N48, N96, and N216 models. For the N144 model that was specifically built and run for this study, one simulation is available. One year of spin-up time is discarded in all simulations so that the reference period for all analyses in this study is 1980-2002.

We use version 2.1 of the Global Precipitation Climatology Project (GPCP) satellite-gauge product as the observational reference data for precipitation, HadSST2 data for sea surface temperature, CRUTEM3 data for land temperature, and evaluate atmospheric fields against ERAInterim data (see also Table 1).

\section{Resolution dependence of the tropical mean climate}

In this section, we give an overview of the mean-state biases of HadGAM1 and of how these biases depend on resolution. At all resolutions, the model qualitatively captures many of the large-scale features of the global precipitation distribution (Fig. 1a-c). This includes the Intertropical Convergence Zone (ITCZ), the South Pacific Convergence Zone (SPCZ) and the midlatitude stormtracks, as well as the subtropical subsidence regions. At the same time, biases can be identified when comparing to the observed precipitation (Fig. 1d-f). There is too much precipitation over the oceans, in particular in the western part of the basins in the tropics. HadGAM1 has pronounced dry biases over the Indian Subcontinent and Southeast Asia including the Maritime Continent. These are long-standing errors in the HadGEM1 family of climate models (e.g., Martin et al. 2006; Shaffrey et al. 2009) and they are of the same order of magnitude as the total model precipitation in some regions (for example, in the Maritime Continent box shown in Fig. 1, the annual mean precipitation is $2.64 \mathrm{~mm} \mathrm{day}^{-1}$ in the $\mathrm{N} 48$ model and $6.23 \mathrm{~mm} \mathrm{day}^{-1}$ in GPCP).

The increase in resolution reduces the magnitude of the biases in the western tropical oceans, the Maritime Continent, and, to a smaller extent, over India. This can be seen by comparing the differences between the N48 and the higher-resolution models (Fig. 1g, h) with the biases shown in Fig. 1d-f. The effect of increased resolution and the biases are of opposite sign in many regions. The difference between the N96 and N144 models is much smaller than the difference between each of these models and the N48 model. There are two reasons that may explain this. Firstly, the increase in resolution from N48 to N96 is a larger step (about 350 to $170 \mathrm{~km}$ grid spacing) than the increase from N96 to N144 (about 170 to $110 \mathrm{~km}$ ). Secondly, the regional mean land fraction is higher in the N144 model (see Sect. 2 and Table 2). Since the warm ocean is the main source of evaporation in the region, the increase in latent heat flux due to the increase in resolution appears to be partly offset by the fact that there is slightly less evaporation from the smaller ocean surface in the N144 model. In the N216 model (Fig. 2), the sign and geographical distribution of 
the precipitation bias are similar to those in the N48-N144 models, while the magnitude of the bias tends to be somewhat smaller. The box over the central part of the Maritime Continent $\left(95.625-140.625^{\circ} \mathrm{E},-8.75\right.$ to $3.75^{\circ} \mathrm{N}$; Fig. 1) corresponds to a region where there is a dry precipitation bias at all resolutions, and where the impact of higher resolution is such as to increase precipitation throughout the region. This domain will be used for the analyses discussed later in the paper.

Figure 3 shows the land fraction, precipitation $P$, evaporation $E, P-E$, and midtropospheric vertical velocity meridionally averaged in a tropical channel (covering the same latitudes as the domain highlighted by the box in Fig. 1). The land fraction shows the approximate location of the African, Maritime, and American continents. At all resolutions, the contrast between a comparatively dry Maritime Continent and wet Indian and West Pacific oceans is larger in HadGAM1 than in GPCP or ERAInterim. The evaporation in the model is larger than in ERA-Interim over the oceans, and about the same over land. Accordingly, the bias in $P-E$ is smaller than the precipitation bias in regions where the precipitation bias is positive (such as the West Pacific), and larger where the precipitation bias is negative (such as the East Pacific). In general, $P-E$ biases follow the precipitation biases, in particular over land. $P-E$, i.e. regions of climatological moisture convergence (divergence), are in turn closely related to regions of ascent (descent) as shown by the midtroposheric vertical velocity. It is notable that the Maritime Continent is a region of time-mean descent in the models, in contrast to ERA-Interim.

The effect of resolution is to reduce the dry bias over the Maritime continent by about one third. There are reductions of similar magnitude of the wet biases over the

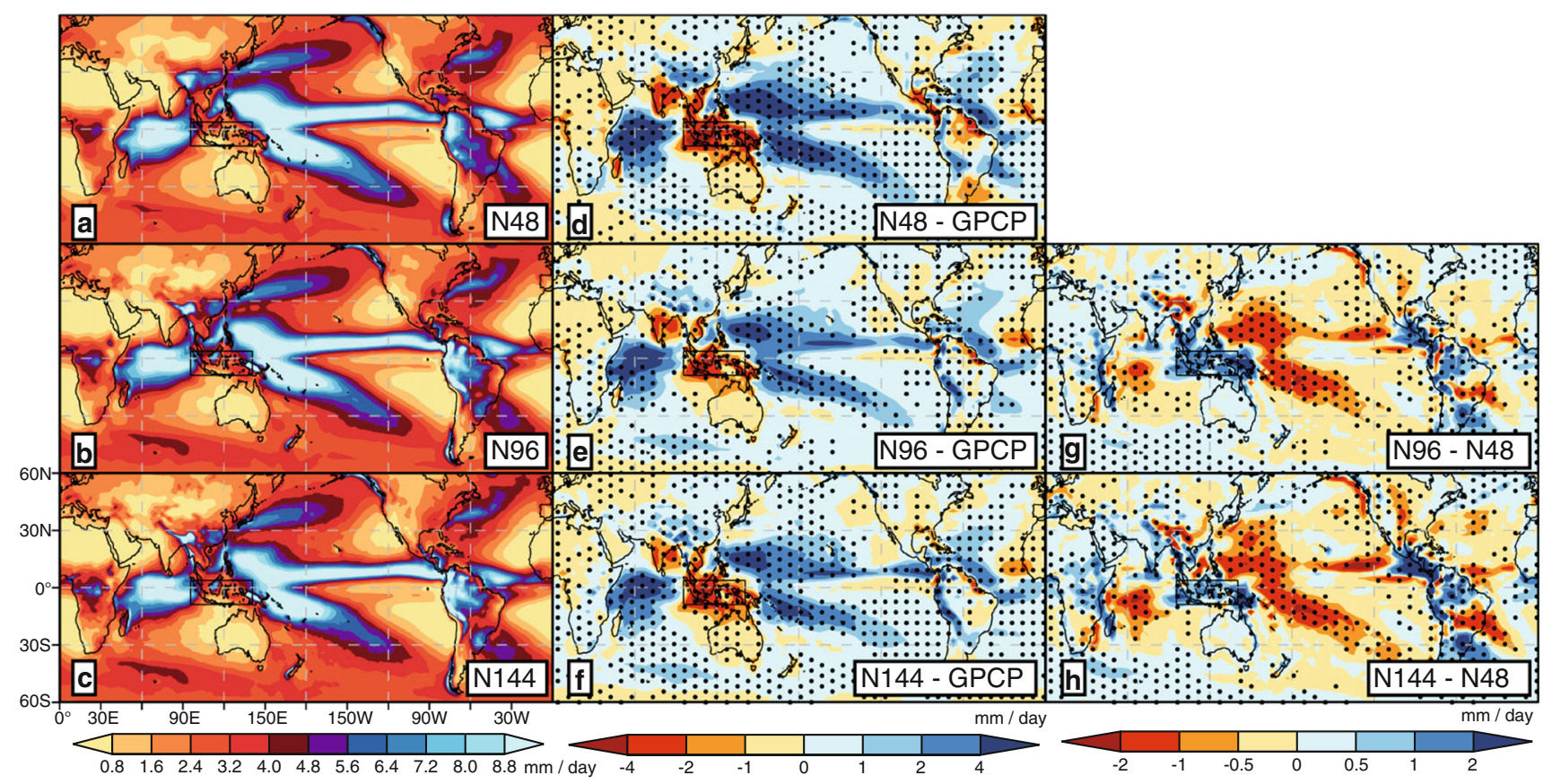

Fig. 1 a-c Annual mean precipitation in the N48, N96, and N144 models, $\mathbf{d}-\mathbf{f}$ biases with respect to GPCP, and $\mathbf{g}, \mathbf{h}$ resolution depence. Here and in subsequent figures: stippling shows grid points where a

paired t-test rejects the null hypothesis of equal means at the $95 \%$ confidence level. A box enclosing the central part of the Maritime Continent $\left(95.625-140.625^{\circ} \mathrm{E},-8.75\right.$ to $\left.3.75^{\circ} \mathrm{N}\right)$ is shown

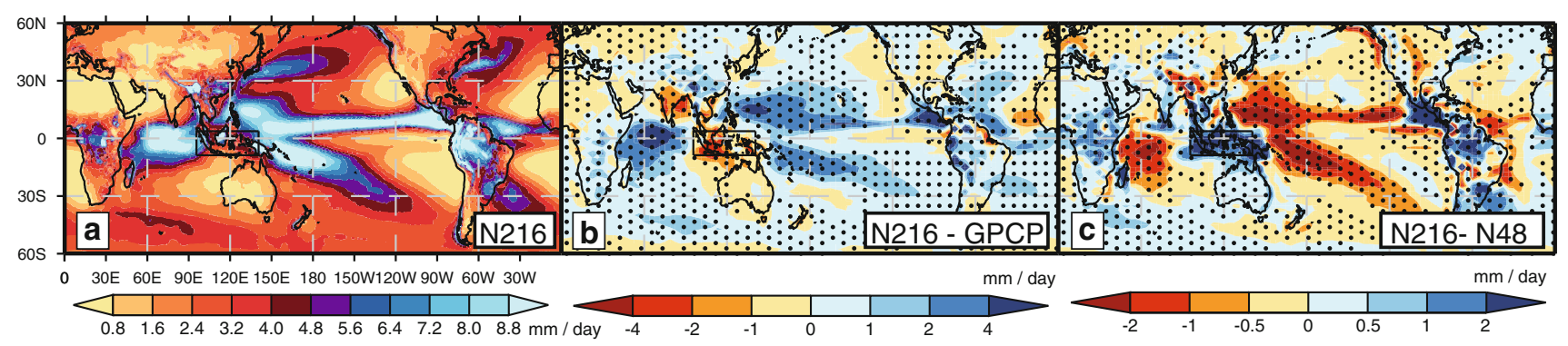

Fig. 2 Precipitation distribution in the N216 model. a Mean, b bias with respect to GPCP, and c difference from the N48 model 


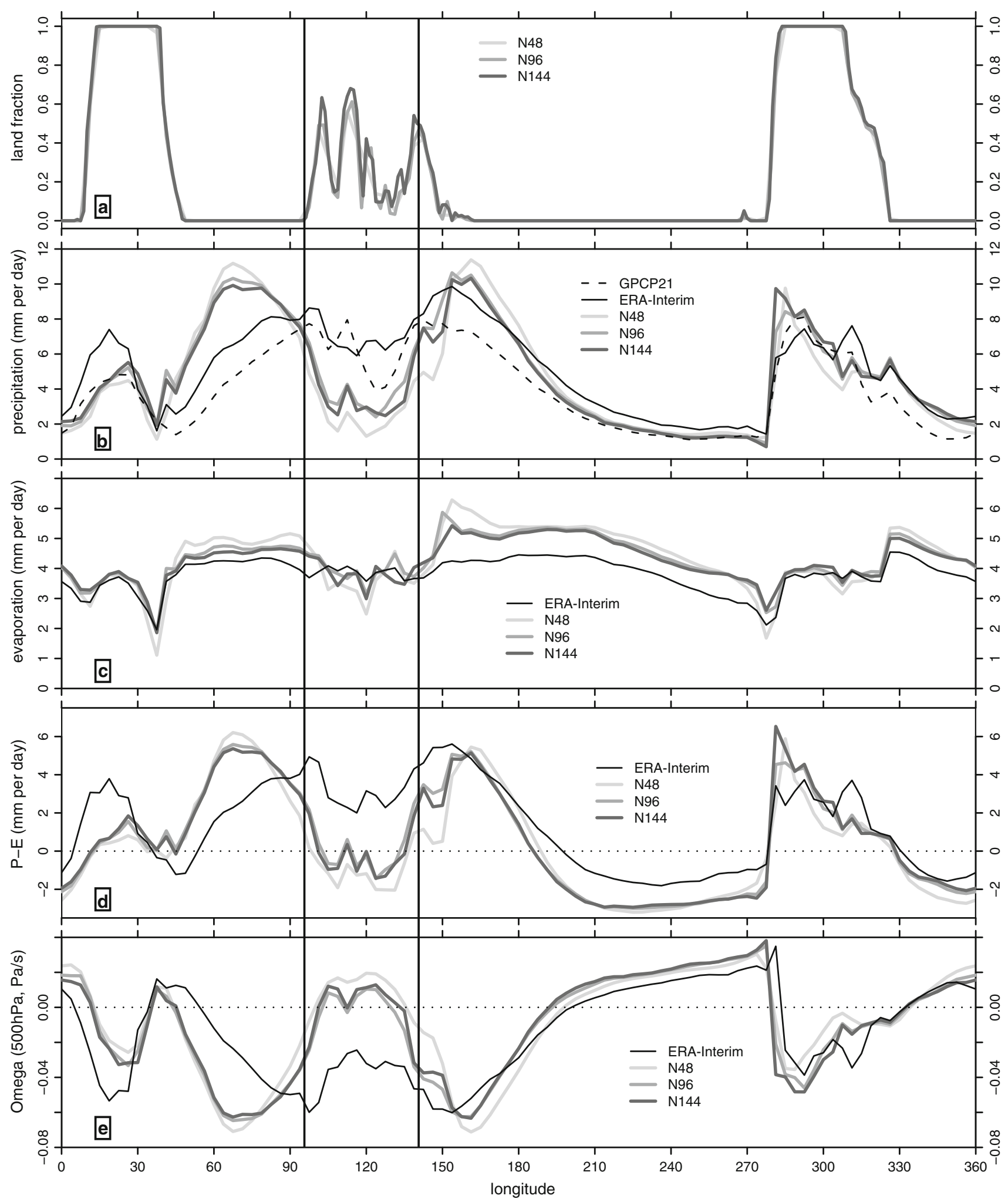

Fig. 3 Mean values of a land fraction, b precipitation $P$, $\mathbf{c}$ evaporation $E, \mathbf{d} P-E$, and e midtropospheric vertical velocity in a tropical channel $\left(-8.75\right.$ to $\left.3.75^{\circ} \mathrm{N}\right)$ versus longitude. Vertical lines shown the analysis domain $\left(95.625-140.625^{\circ} \mathrm{E}\right)$

Western Indian and West Pacific oceans that are associated with the Maritime Continent via the Walker circulation. The increase with resolution of precipitation over the
Maritime Continent is associated with an increase of $P-E$ by roughly the same amount, and larger ascent/smaller descent. 


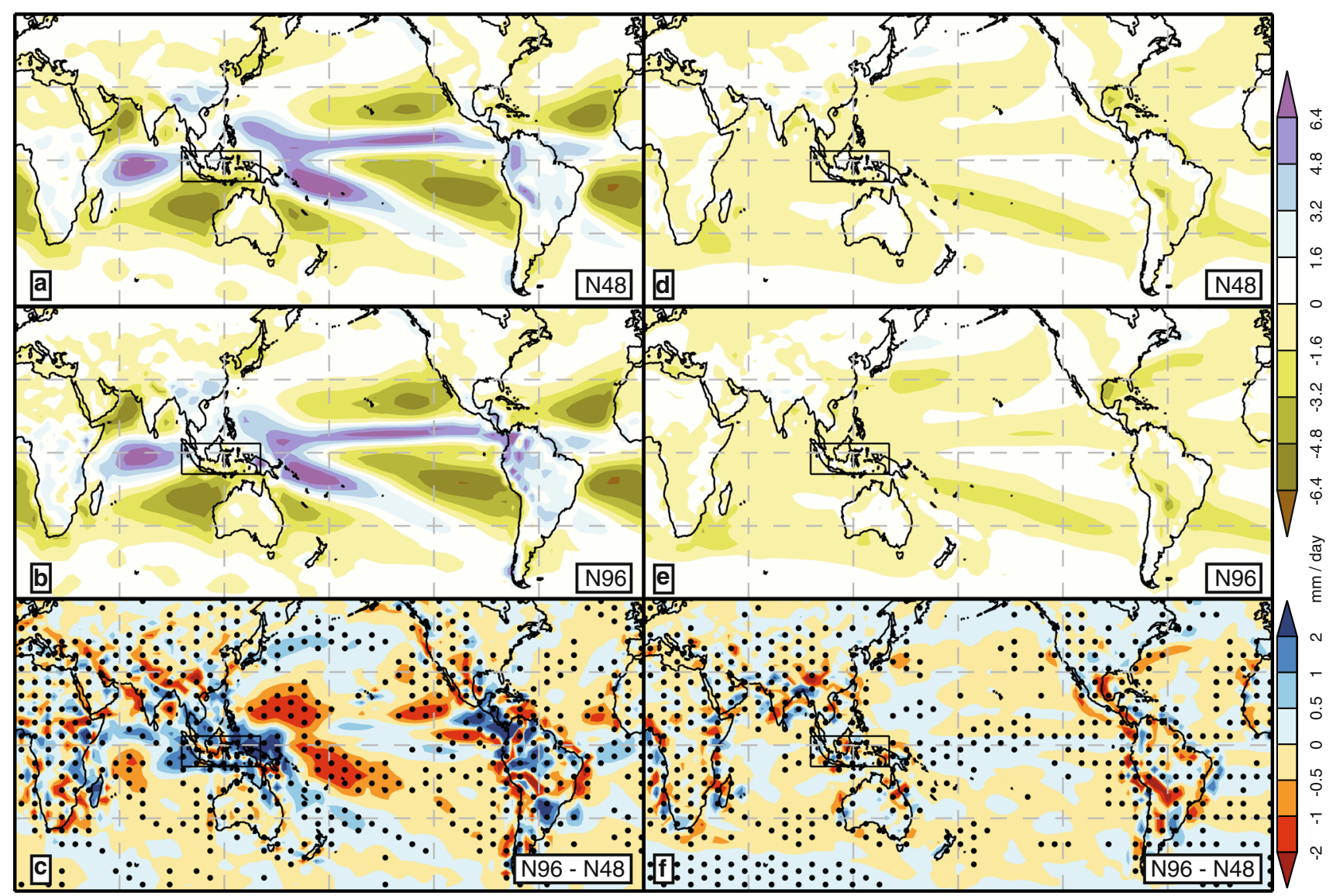

Fig. 4 Moisture-flux convergence in the N48 and N96 models. a, b Mean part and d, e eddy part for the two resolutions, and c, f difference in the mean and eddy part between the resolutions

We formulate two hypotheses that may explain the observed resolution dependence. First, we test if higher resolution allows for more moisture to be transported in atmospheric "eddies". The second hypothesis concerns the surface boundary conditions prescribed to the atmospheric model. These surface fields include orographic fields, soil and vegetation parameters, and the fractional land-sea mask. As the resolution is increased, surface fields are prescribed with greater detail. It is clear that these changes have the potential to modify many aspects of the simulated climate such as the atmospheric circulation, the surface fluxes, and also the precipitation (e.g., Neale and Slingo 2003). We test the first hypothesis in the remainder of this section; the second hypothesis is addressed in terms of sensitivity experiments described in Sect. 4.

\subsection{Mean and eddy transport of moisture}

We have seen that the resolution dependence of $P-E$ is very similar to the resolution dependence of precipitation. Since $\nabla \cdot(q \mathbf{v})=P-E$, moisture convergence is a suitable quantity to investigate the role of eddies for the observed resolution dependence. To this end, we decompose the moisture flux convergence into mean and eddy component

$$
-\nabla \cdot \int_{z} q \mathbf{v} \mathrm{d} m(z)=-\nabla \cdot \int_{z}(\underbrace{\bar{q} \overline{\mathbf{v}}}_{\text {mean' }}+\underbrace{q^{\prime} \mathbf{v}^{\prime}}_{\text {'eddy' }}) \mathrm{d} m(z),
$$

where $q=\bar{q}+q^{\prime}$ and $\mathbf{v}=\overline{\mathbf{v}}+\mathbf{v}^{\prime}$ is the decomposition of the specific humidity and the horizontal velocity into the monthly-mean and eddy (deviation from the monthly mean at each time step) part. The $\bar{q} \mathbf{v}^{\prime}$ and $q^{\prime} \overline{\mathbf{v}}$ terms in Eq. (1) are zero by construction. The integration is carried out over the whole mass of air in the atmospheric column. The result of this decomposition is shown in Fig. 4 for the N48 and N96 models. In the tropics, the dominant contribution to moisture convergence is in the mean term. In agreement with the previous discussion, the effect of increasing the resolution is to increase mean moisture convergence over the Maritime Continent, and to decrease it over the neighbouring ocean areas (Fig. 4c). The resolution dependence of mean moisture convergence is very similar to the resolution dependence of the precipitation shown in Fig. 1 and it is larger than the differences in the eddy part shown in Fig. 4f. The same results are obtained for the N144 model 
(not shown). This suggests that moisture transported in eddies does not constitute the main part of the climatological resolution dependence, and so we reject the first hypothesis formulated above.

\section{Role of surface boundary conditions}

We now turn to the second hypothesis formulated in the preceeding section and investigate the role of prescribed (or seasonally varying) surface boundary conditions at different resolutions. As discussed above, some sensitivity to the surface fields can be expected, yet it is not straightforward to estimate a priori what the net consequences for the simulated climate should be. We therefore conduct the sensitivity experiments described below.

\subsection{Methodology}

As the resolution of a model is increased, boundary data are prescribed at a higher resolution, and a part of the subgrid-scale variability in the boundary fields at the lower resolution will be explicitly represented at the higher resolution. We aim to quantify the impact this has on the simulated climate, and to separate this effect from other changes due to increased resolution. To this end, we use the high-resolution (N96 or N144) atmospheric models, but regionally replace surface boundary conditions by their coarse-resolution (N48) counterpart. This is illustrated in Fig. 5 for the fractional land-sea mask. The top panels (Fig. 5a, c) show the original land-sea masks of the N96 and N144 models, and the bottom panels (Fig. 5b, d) show the land-sea masks obtained by replacing the high-resolution mask by the coarse-resolution mask over the Maritime Continent (in the region outlined by the black box). To retain the coarse-resolution structure of the N48 boundary data, the value of a single N48 grid cell is indentically assigned to all corresponding grid cells at the higher resolution. For the N144 model, this is straightforward since nine grid cells of the N144 model exactly overlap one grid cell of the N48 model as shown in Fig. 6a. For the N96 model, there are a number of ways to match an N48 cell to four N96 cells, and we choose to shift the N48 values to the southwest by one half of the grid spacing of the N96 model (Fig. 6b).

Coarse surface boundary fields are introduced for the land fraction, for orographic fields, for soil moisture, soil temperature, and a number of soil parameters; as well as for leaf-area index, canopy height, and fractional coverage by vegetation types. We refer to the experiments where all these surface boundary fields have been replaced by the N48 fields as 'N96DA' and 'N144DA'. Additionally, we test the effect of introducing coarse-resolution orographic fields only (and leaving all other surface boundary fields unchanged). We conduct this experiment with the N96 model only and refer to it as 'N96DO'.

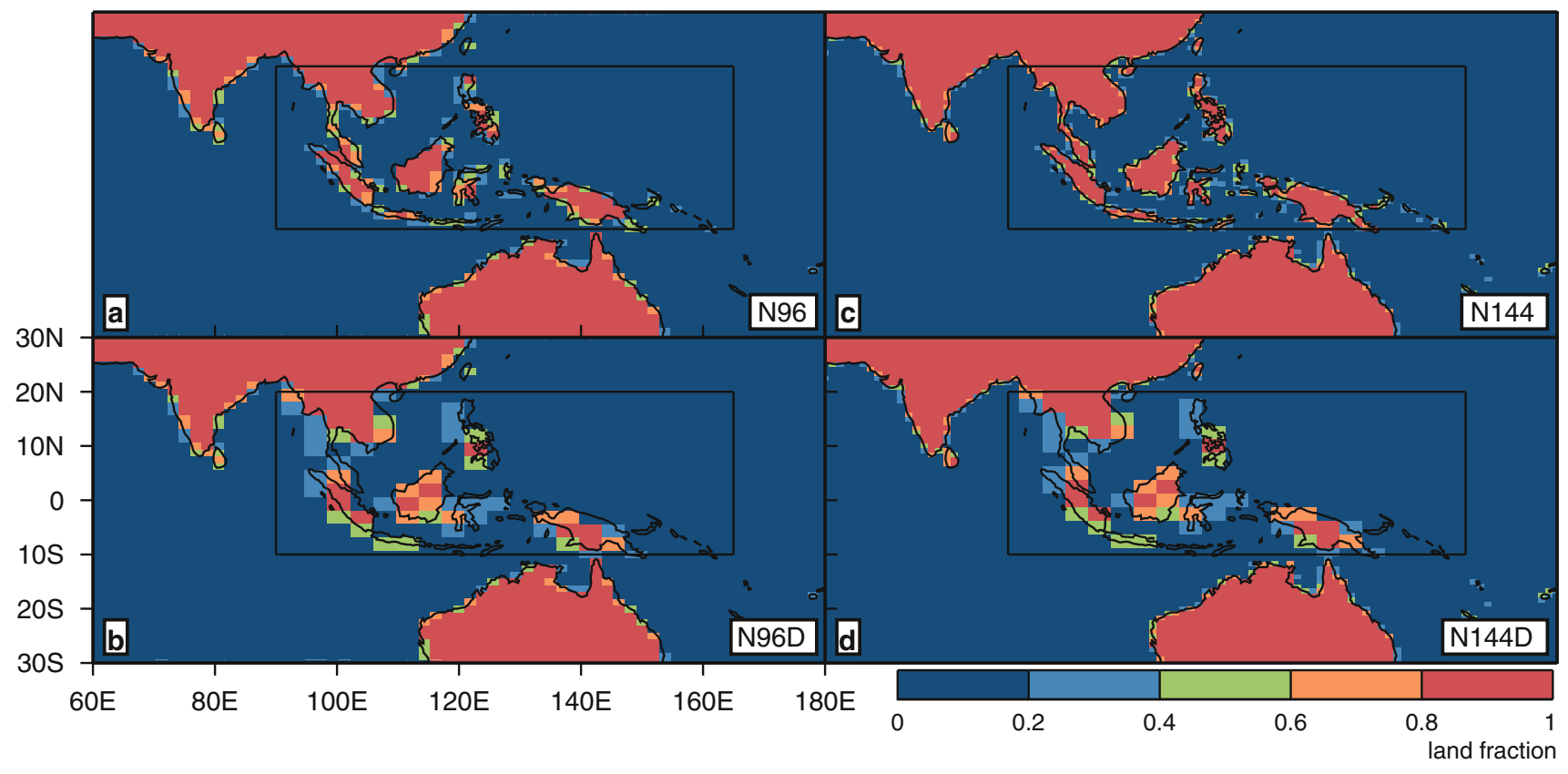

Fig. 5 Modification of the fractional land-sea mask over the Maritime Continent. a Original mask of the N96 model, b the mask of the N48 model is regionally introduced into the N96 model, c original mask of the N144 model, $\mathbf{d}$ the mask of the N48 model is regionally introduced into the N144 model mask. Coarse surface boundary fields are introduced throughout $90-165^{\circ} \mathrm{E}$ and -10 to $20^{\circ} \mathrm{N}$ (box) 

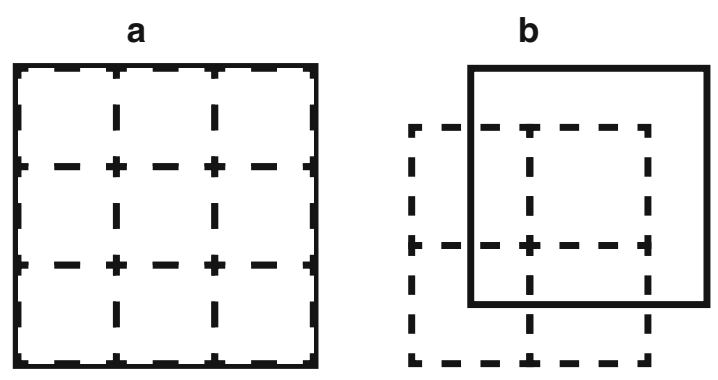

Fig. 6 Schematic of the relative alignment of grid cells in a the N48 and N144 models, and b the N48 and N96 models

\subsection{Results of the sensitivity experiments}

The impact of introducing coarse surface boundary conditions on the mean precipitation is shown in Fig. 7. Over the Maritime Continent, where the modified surface fields have been applied, coarse boundary conditions lead to a reduction of precipitation, both in the N96DA and N144DA experiments. In the Indian Ocean, over the Maritime Continent, and the West Pacific, the response to coarsening the surface fields is similar to the impact of resolution (compare Figs. 1g, h, 7a, b). This suggests that the change in the model-simulated climate with resolution is largely due to the associated change in the surface boundary conditions. The sensitivity is not dominated by the orographic fields as shown by the smaller and more localized response in the N96DO experiment shown in Fig. 7c. This implies that the response is largely due to the different representation of the coastline and of land-surface parameters at different resolutions.

We proceed with an analysis of the surface climate in the central Maritime Continent region introduced in Fig. 1. Figure 8 shows the precipitation, temperature, net radiation, and latent heat flux at the surface. When compared with the observed precipitation and the re-analysis data, all model experiments show less precipitation, higher landsurface temperature, and larger net surface radiation. The latent heat flux over land is smaller than in ERA-Interim, whereas the bias is relatively small over the ocean where the surface temperature is prescribed. The biases in all quantities are consistent with a drier and warmer climate in HadGAM1 than seen in ERA-Interim and observations.

The effect of higher resolution is to decrease the model biases (compare the N96 and N144 model with the N48 model for the following discussion). The precipitation bias with respect to GPCP in the N96 model is about $40 \%$ smaller than in the N48 model $[(4.06-2.64) /(6.23-$ 2.64)]. The reduction of the bias in the N144 model is somewhat smaller, about $30 \%$. In both the N96 and the N144 model, the dry precipitation bias is reduced by a larger amount over land than over the ocean.

The biases in the other variables undergo a consistent reduction with resolution. The land-surface temperature

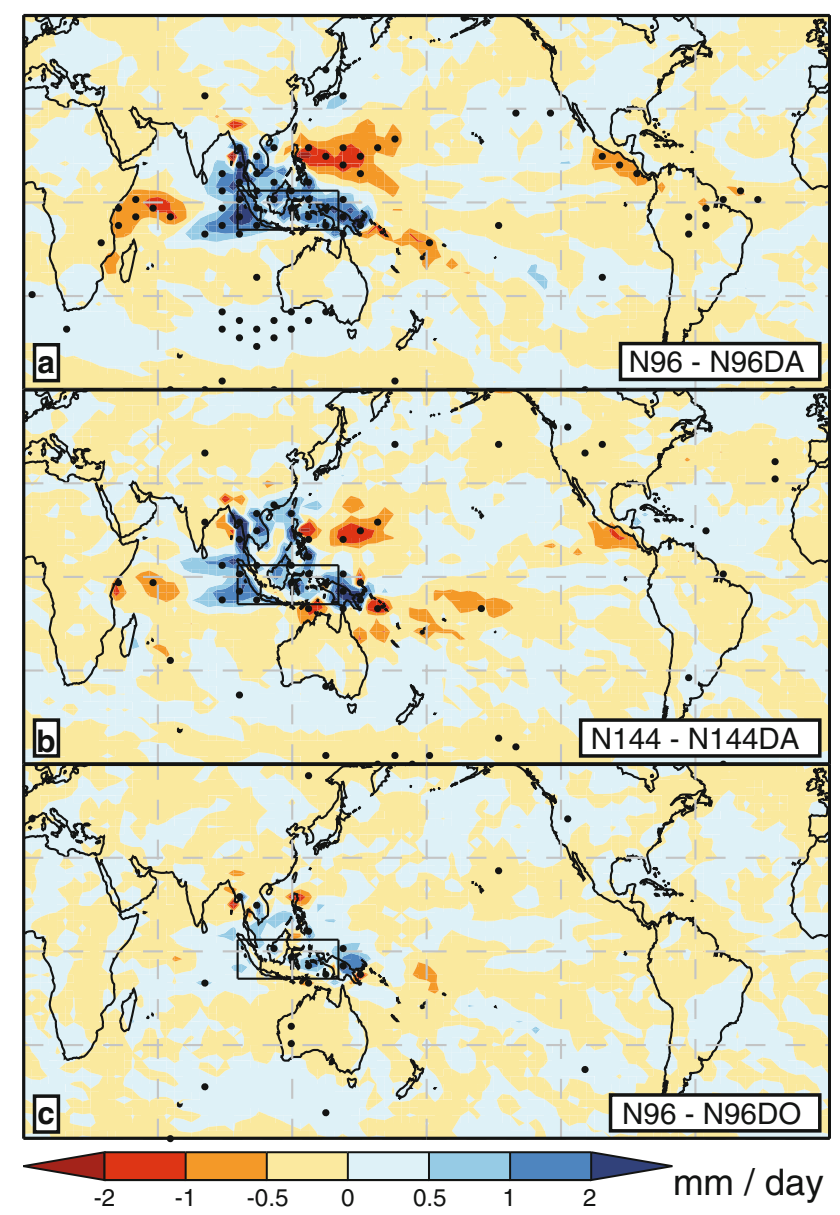

Fig. 7 Change in mean precipitation due to the introduction of coarse surface boundary conditions over the Maritime Continent. a For the N96 and b for the N144 model, all surface boundary fields are replaced by coarse fields. c Only orographic fields are replaced by coarse fields in the N96 model

decreases below the value of the sourrounding oceans bringing the N96 and N144 models into better agreement with ERA-Interim than N48. Net radiation descreases over land and changes only little over the ocean. Latent heating increases with resolution, albeit only by a very small amount in the N144 model over the ocean. The overall effect of higher resolution is a cooler and moister model climate in better agreement with the reference data.

Much of the resolution dependence described above can also be seen in the sensitivity experiments using coarse surface boundary fields. For example, the precipitation both over the land and the ocean is only slightly larger in the N96DA and N144DA experiments than in the N48 model. Net radiation over land increases due to the introduction of coarse surface fields, whereas the latent heat flux decreases both over land and ocean. This further suggests that the improvement with higher resolution of the simulated climate of the Maritime Continent is predominantly 

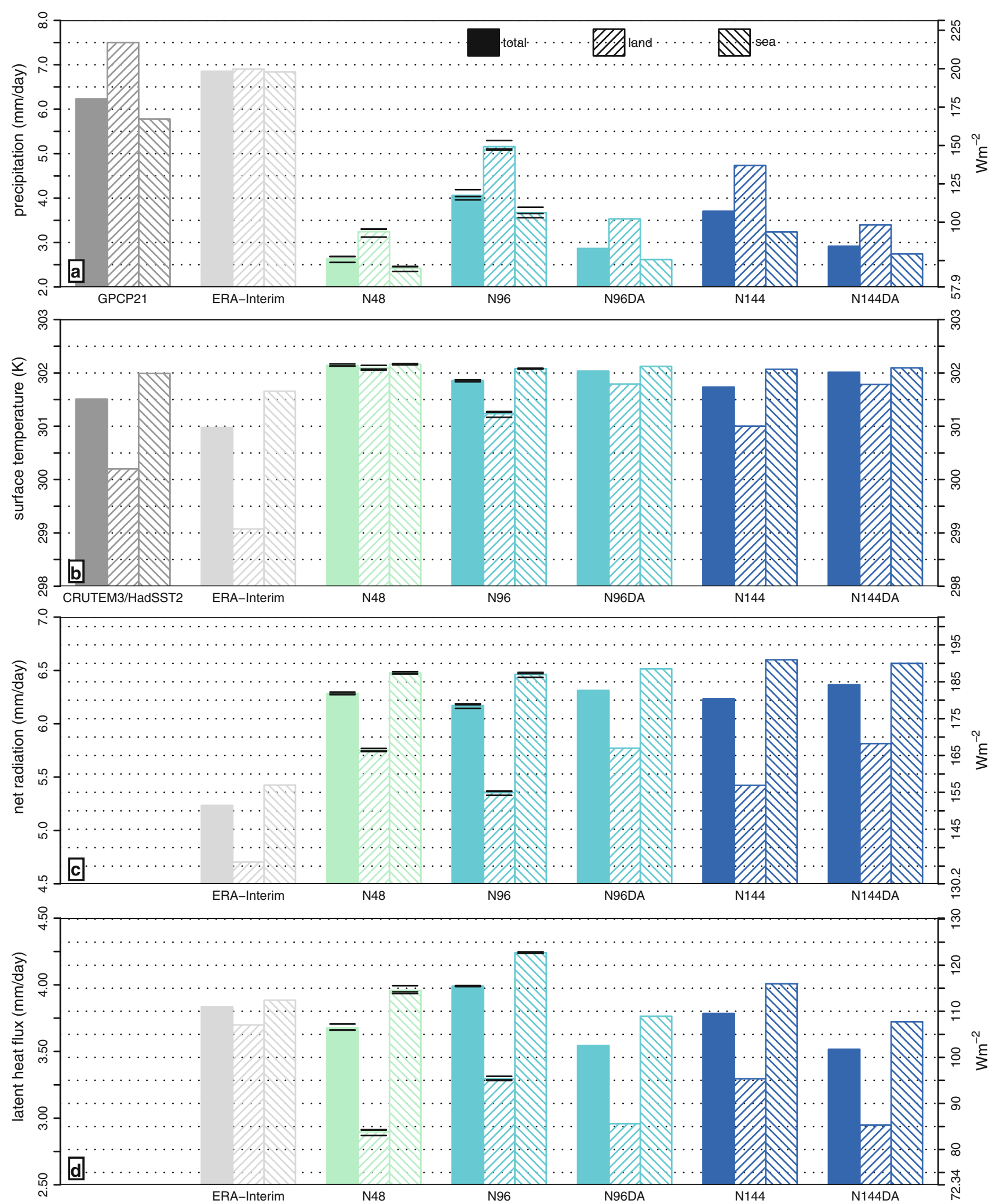

Fig. 8 a Precipitation, b temperature, $\mathbf{c}$ net radiation (longwave plus shortwave), and d latent heat flux at the surface in the central Maritime Continent $\left(95.625-140.625^{\circ} \mathrm{E},-8.75\right.$ to $\left.3.75^{\circ} \mathrm{N}\right)$. Vertical bars show mean values for the whole domain (solid) and for land and sea areas separately (hatched). Black lines show means for individual ensemble members. Conversion between $\mathrm{mm} \mathrm{day}^{-1}$ and $\mathrm{W} \mathrm{m} \mathrm{m}^{-2}$ is based on a latent heat of condensation of $2.5 \times 10^{6} \mathrm{~J} \mathrm{~kg}^{-1}$. Ordinates do not start with zero 
due to the fact that surface boundary conditions are prescribed in greater detail as the resolution is increased.

\subsection{Discussion of mechanisms}

Further insight into the increase in the Maritime Continent precipitation and surface latent heat flux with resolution can be gained from a more detailed consideration of the land surface scheme. In common with many other climate models, HadGEM1 uses a coastal-tiling surface scheme (Martin et al. 2006), where coastal grid-boxes are partitioned into land and ocean fractional tiles at the surface level. Diagnostic fields used in the calculation of surface fluxes have different values for the land and sea parts at the surface of the coastal grid-box, whereas no distinction between land and sea is made at the lowest atmospheric level (Fig. 9). The vertical exchange coefficients governing the fluxes depend on quantities both at the surface and at the lowest atmospheric level, and therefore also have different values over the land and sea parts of the coastal grid-box.

The formulation of the coastal tiling scheme can result in unrealistic surface fluxes over coastal grid-boxes (Strachan 2007). We illustrate this here for the surface latent heat flux in the N144 model (Fig. 10). Figure 10a shows the land fraction; the colour bar is such that the lowest (highest) level corresponds to pure sea (land) grid-boxes, and the intermediate three levels correspond to coastal grid-boxes. The surface latent heat flux is shown in Fig. 10b. Over the coastal grid-boxes surrounding the major Maritime Continent islands the latent heat flux is smaller than over nearby grid-boxes over the open sea and in the interior of the islands.

Over coastal grid-boxes, the latent heat flux is the mean of the flux over the sea and land parts of the grid-box weighted by the land fraction. Figure 10c shows the latent heat flux from pure sea grid-boxes and from the sea part of coastal grid-boxes, and Fig. 10d shows the complementary latent heat flux from pure land grid-boxes and the land part of coastal grid-boxes. Over most of the coastal grid-boxes,

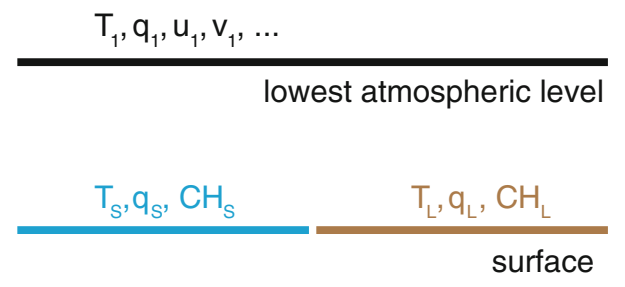

Fig. 9 Schematic of the coastal tiling scheme. At surface level, the model grid-box is devided into a land and a sea part, with pertinent variables such as temperature $T$ and specific humidity $q$, and also exchange coefficients $\mathrm{CH}$. No distinction between land and sea is made at the lowest atmospheric level

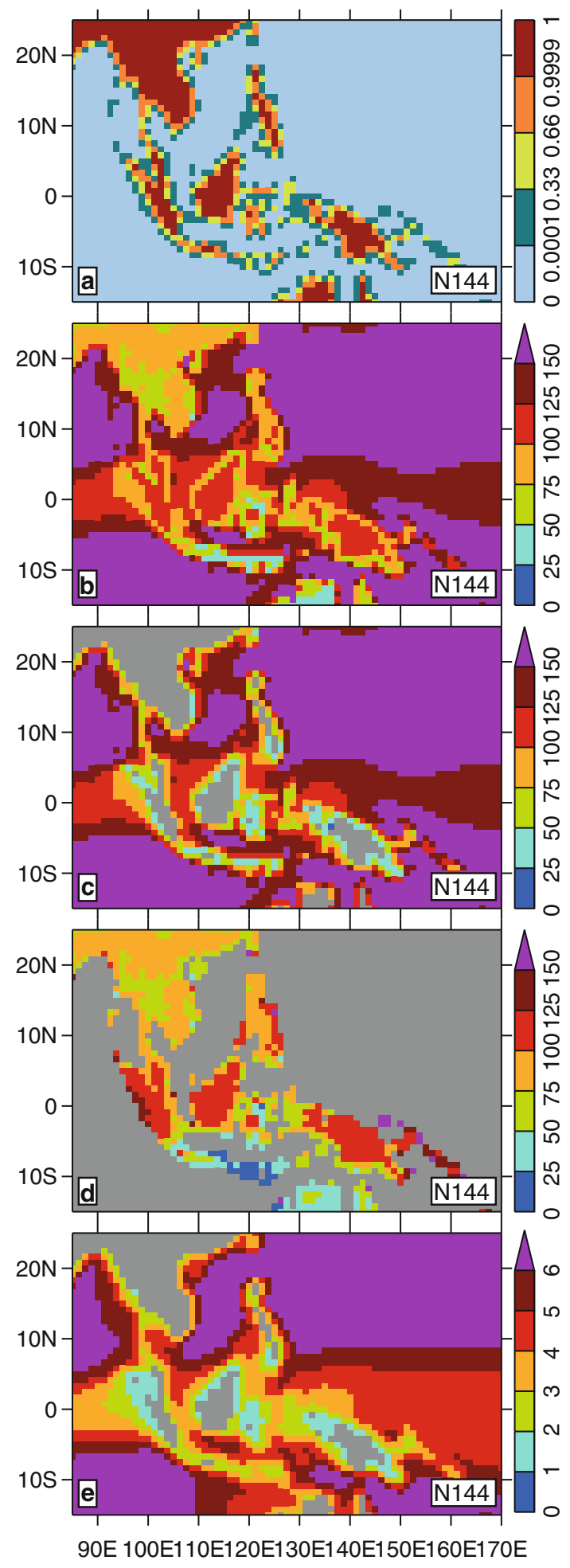

Fig. 10 N144 model. a Land fraction, annual means of b surface latent heat flux $\left(\mathrm{W} \mathrm{m}^{-2}\right)$, $\mathbf{c}$ per unit area surface latent heat flux over pure sea grid-boxes and the sea part of coastal grid-boxes $\left(\mathrm{W} \mathrm{m}^{-2}\right)$, d per unit area surface latent heat flux over pure land grid-boxes and the land part of coastal grid-boxes $\left(\mathrm{W} \mathrm{m}^{-2}\right)$, e wind speed at $10 \mathrm{~m}$ over pure sea and coastal grid-boxes $\left(\mathrm{m} \mathrm{s}^{-1}\right)$. Pure land or sea gridboxes where the respective diagnostic is not defined are shown in grey 
the latent heat flux is substantially smaller over the sea part of the grid-box than over the land part. This shows that the reduction of the latent heat flux over coastal grid-boxes (Fig. 10b) is largely due to the small latent heat flux over the sea part of coastal grid-boxes (Fig. 10c).

To investigate further, the $10-\mathrm{m}$ wind speed over pure sea and coastal grid-boxes is shown in Fig. 10e. The 10-m wind speed is smaller over coastal grid-boxes than over pure sea grid-boxes. Comparison of Fig. 10b, c, e shows that the spatial variation of the wind is fairly closely associated with that of the latent heat flux over both sea and coastal grid-boxes. The reduction of the latent heat flux over the coastal grid-boxes is consistent with the formulation of the coastal tiling scheme: It is plausible that over coastal grid-boxes the increased surface roughness over the land part of the grid-box will reduce the wind speed at the lowest model level. The reduced lowest model-level wind is then used to calculate a reduced surface latent heat flux over the sea part of the coastal grid-box.

It is clear that the suppression of the latent heat flux over coastal points can lead to resolution dependencies. To show this explicitly, the differences in surface latent heat flux averaged over $\mathrm{N} 48$ grid-boxes were compared between the N144 control and the degraded land surface (N144DA) experiments over the Maritime Continent. The differences in the surface latent heat flux as a function of land fraction can be seen in Fig. 11. When the land fraction within a N48 gridbox is close to zero or one (i.e. all sea or land) the surface latent heat fluxes in the N144 control and N144DA experiment are similar on average. For an N48 grid-box with a land fraction of 0.5 (i.e. $50 \%$ land and $50 \%$ ocean) the latent heat flux in the $\mathrm{N} 144$ control experiment is roughly $15-20 \mathrm{~W} \mathrm{~m}^{-2}$ larger than that of the N144DA experiment. We have verified that this difference is statistically significant.

Since the Maritime Continent is a region of complex landsea contrasts, a large number of grid-boxes are prescribed as being coastal. As the resolution increases then naturally the fraction of the prescribed coastal grid-boxes decreases (Table 3). Subsequently this leads to an increase in the surface latent heat flux averaged over the Maritime Continent. We argue that the response seen in the precipitation is due to the direct forcing of the surface wind and turbulent fluxes by the modified surface boundary fields, and a feedback associated with an enhancement of moisture convergence and the Walker circulation. We note in passing that the fraction of coastal grid-boxes is comparatively similar in the N96 and N144 models (Table 3), which provides an additional possible explanation of the rather small difference in the mean state between these two models discussed in Sect. 3 .

These results suggest two possible conclusions. Firstly, by reducing the need to parametrise coastal regions, increasing the resolution of climate models enables land surface schemes to better represent regions such as the

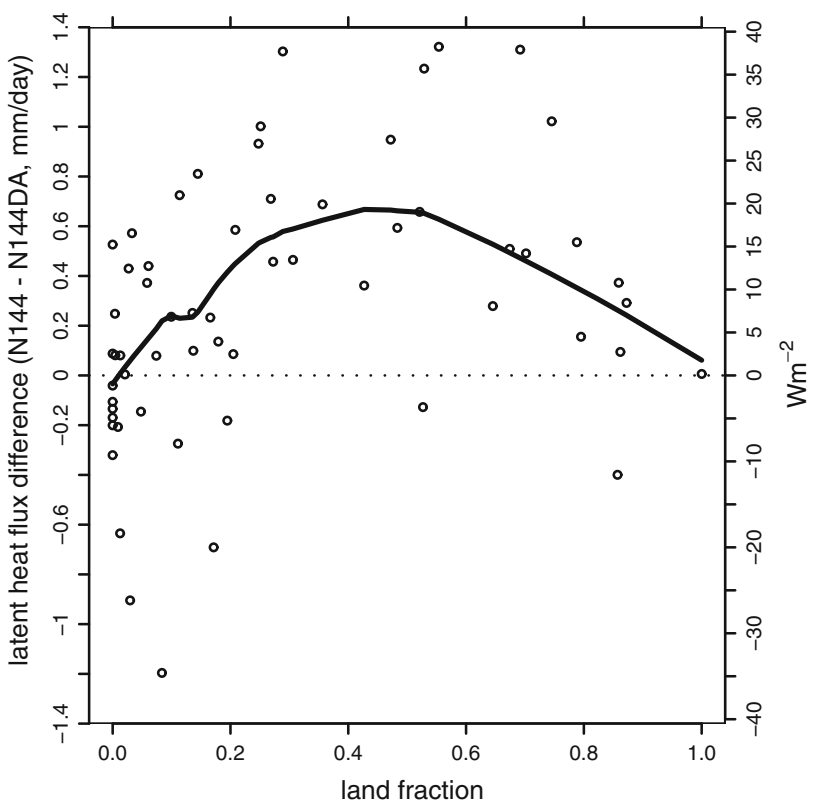

Fig. 11 Difference in the annual-mean latent heat flux between the N144 control simulation and the N144 simulation with coarse surface boundary fields over the Maritime Continent (N144DA). Each point in the scatterplot corresponds to the mean of $3 \times 3$ N144 grid-boxes, i.e. to a box of the N48 grid (as in Fig. 6a). The black line is obtained by LOWESS smoothing with span $f=0.5$ (Cleveland 1979, 1981)

Table 3 Area fraction (\%) of coastal grid-boxes at different resolutions, averaged over the whole globe and over the Maritime Continent $\left(95.625-140.625^{\circ} \mathrm{E},-8.75\right.$ to $\left.3.75^{\circ} \mathrm{N}\right)$

\begin{tabular}{lrrr}
\hline & N48 & N96 & N144 \\
\hline Global & 15.5 & 8.2 & 7.5 \\
Maritime Continent & 71.7 & 46.5 & 41.7 \\
\hline
\end{tabular}

Maritime Continent and to reduce associated long-standing biases in tropical precipitation. Secondly, these results also highlight a need to improve land surface schemes so that coastal tiling parametrisations do not exhibit such large resolution dependencies when used in coarse resolution climate models. Indeed, a so-called "buddy" scheme for coastal grid-boxes has been introduced in a more recent model version (HadGEM3-GA3.0, Walters et al. 2011), which uses an average wind speed over neighbouring gridboxes to split the wind speed at the lowest atmospheric level into separate land and sea contributions. This enhances the wind speed over the sea part of the grid-box giving improved scalar fluxes there and a better mean state over the Maritime Continent region.

\section{Summary and discussion}

We have investigated how tropical precipitation biases in an atmosphere-only GCM (AGCM) depend on the model's 
horizontal resolution. To this end, we have used ensembles of simulations of present-day climate with the HadGAM1 AGCM at grid spacings between about 350 and $110 \mathrm{~km}$, but otherwise very similar model formulation. We find that

- the increase in resolution reduces long-standing tropical precipitation biases in HadGAM1. For example, the dry bias over the Maritime Continent is reduced by about one third, and associated improvements are seen over the Western Pacific and western Indian oceans.

- the increase in precipitation over the Maritime Continent at higher resolution is associated with an enhancement of the Walker circulation and increased moisture convergence. Decomposition of the moisture convergence into its mean and eddy parts shows that the resolution dependence is predominantly seen in the mean part.

- the resolution dependence is largely due to the specification of better resolved surface boundary conditions (such as the land-sea mask, soil and vegetation parameters) as the resolution is increased. This finding is based on sensitivity experiments where we have replaced surface boundary conditions in higher resolution models (N96 and N144 resolutions) with those from a low (N48) resolution model over the Maritime Continent. The sensitivity is not mainly associated with orographic surface fields as seen in an experiment where only these fields are changed.

In this study we find that the surface latent heat flux depends nonlinearly on the land fraction in the HadGAM1 models. Over the Maritime Continent, the latent heat flux over coastal points is smaller than that over pure land or ocean points. As the model resolution increases, there are relatively fewer coastal points and therefore the regionally averaged latent heat flux increases. This suggests that increasing the resolution of climate models improves the representation of complex and heterogeneous regions, such as the Maritime Continent, by reducing the need to parameterise coastal areas. This can have sizable impacts on long-standing biases in the ability of climate models to simulate tropical precipitation.

It was also found that a rather similar reduction in precipitation biases was found in the N96 and N144 models. This suggests that the sensitivity of Maritime Continent precipitation to resolution in the HadGEM1 family of models may be reduced for resolutions higher than N96. This result is also consistent with preliminary results from an N216 resolution model. One key question is whether the conclusions of this study will be found in other atmospheric climate models that have very different formulations and parameterisations. It will be particularly useful to address this question with climate model experiments that systematically test the impact of model resolution on the representation of the climate system. Future research will test the conclusions of this study in a new set of climate model experiments with the HadGEM3 climate model (Hewitt et al. 2011) currently being performed (Mizielinski et al., submitted to Geosci Model Dev) with horizontal resolutions ranging from $\mathrm{N} 48(\sim 350 \mathrm{~km}$ at low latitudes) all the way up to $\mathrm{N} 512(\sim 30 \mathrm{~km})$.

Acknowledgments The models described were developed from the Met Office Hadley Centre Model by the UK High-Resolution Modelling (HiGEM) Project and the UK Japan Climate Collaboration (UJCC). HiGEM is supported by a NERC High Resolution Climate Modelling Grant (R8/H12/123). UJCC was supported by the Foreign and Commonwealth Office Global Opportunities Fund, and this work has been conducted within the Met Office-NERC Joint Weather and Climate Research Programme (JWCRP). Model integrations were performed using the Japanese Earth Simulator supercomputer, supported by JAMSTEC, and at the UK National Supercomputing Service (HECToR). Thank you to the British Atmospheric Data Centre for hosting our data, ECMWF for providing ERA-Interim reanalysis, and to NCAS Computational Modelling Services.

Open Access This article is distributed under the terms of the Creative Commons Attribution License which permits any use, distribution, and reproduction in any medium, provided the original author(s) and the source are credited.

\section{References}

Adler RF, Huffman GJ, Chang A, Ferraro R, Xie PP, Janowiak J, Rudolf B, Schneider U, Curtis S, Bolvin D, Gruber A, Susskind J, Arkin P, Nelkin E (2003) The Version-2 Global Precipitation Climatology Project (GPCP) Monthly Precipitation Analysis (1979Present). J Hydrometeorol 4(6):1147-1167. doi:10.1175/ 1525-7541(2003)004<1147:TVGPCP $>2.0 . C O ; 2$

Boville BA (1991) Sensitivity of simulated climate to model resolution. J Clim 4(5):469-485. doi:10.1175/1520-0442(1991) $004<0469$ :SOSCTM $>2.0 . \mathrm{CO} ; 2$

Brohan P, Kennedy JJ, Harris I, Tett SFB, Jones PD (2006) Uncertainty estimates in regional and global observed temperature changes: a new data set from 1850. J Geophys Res 111(D12):D12106. doi:10.1029/2005JD006548

Cleveland WS (1979) Robust locally weighted regression and smoothing scatterplots. J Am Stat Assoc 74(368):829. doi:10. $2307 / 2286407$

Cleveland WS (1981) LOWESS: a program for smoothing scatterplots by Robust locally weighted regression. Am Stat 35(1):54. doi: $10.2307 / 2683591$

Dee DP, Uppala SM, Simmons AJ, Berrisford P, Poli P, Kobayashi S, Andrae U, Balmaseda MA, Balsamo G, Bauer P, Bechtold P, Beljaars ACM, van de Berg L, Bidlot J, Bormann N, Delsol C, Dragani R, Fuentes M, Geer AJ, Haimberger L, Healy SB, Hersbach H, Hólm EV, Isaksen L, Kållberg P, Köhler M, Matricardi M, McNally AP, Monge-Sanz BM, Morcrette JJ, Park BK, Peubey C, de Rosnay P, Tavolato C, Thépaut JN, Vitart F (2011) The ERA-Interim reanalysis: configuration and performance of the data assimilation system. Q J R Meteorol Soc 137(656):553-597 
Demory ME, Vidale PL, Roberts MJ, Berrisford P, Strachan J, Schiemann R, Mizielinski MS (2013) The role of horizontal resolution in simulating drivers of the global hydrological cycle. Clim Dyn. doi:10.1007/s00382-013-1924-4

Gent PR, Danabasoglu G, Donner LJ, Holland MM, Hunke EC, Jayne SR, Lawrence DM, Neale RB, Rasch PJ, Vertenstein M, Worley PH, Yang ZL, Zhang M (2011) The community climate system model version 4. J Clim 24(19):4973-4991. doi:10.1175/ 2011JCLI4083.1

Hack JJ, Caron JM, Yeager SG, Oleson KW, Holland MM, Truesdale JE, Rasch PJ (2006) Simulation of the global hydrological cycle in the CCSM Community Atmosphere Model version 3 (CAM3): mean features. J Clim 19(11):2199-2221. doi:10.1175/JCLI3755.1

Held IM, Soden BJ (2006) Robust responses of the hydrological cycle to global warming. J Clim 19(21):5686-5699. doi:10.1175/ JCLI3990.1

Hewitt HT, Copsey D, Culverwell ID, Harris CM, Hill RSR, Keen aB, McLaren AJ, Hunke EC (2011) Design and implementation of the infrastructure of HadGEM3: the next-generation Met Office climate modelling system. Geosci Model Dev 4(2):223-253. doi:10.5194/gmd-4-223-2011

Huffman GJ, Adler RF, Bolvin DT, Gu G (2009) Improving the global precipitation record: GPCP version 2.1. Geophys Res Lett 36(17):L17808. doi:10.1029/2009GL040000

Johns TC, Durman CF, Banks HT, Roberts MJ, McLaren AJ, Ridley JK, Senior CA, Williams KD, Jones A, Rickard GJ, Cusack S, Ingram WJ, Crucifix M, Sexton DMH, Joshi MM, Dong BW, Spencer H, Hill RSR, Gregory JM, Keen AB, Pardaens AK, Lowe JA, Bodas-Salcedo A, Stark S, Searl Y (2006) The New Hadley Centre Climate Model (HadGEM1): evaluation of coupled simulations. J Clim 19(7):1327-1353. doi:10.1175/ JCLI3712.1

Manabe S, Smagorinsky J, Holloway JL, Stone HM (1970) Simulated climatology of a general circulation model with a hydrologic cycle. Mon Weather Rev 98(3):175-212. doi:10.1175/15200493(1970)098<0175:SCOAGC $>2.3 . C O ; 2$

Martin GM, Ringer MA, Pope VD, Jones A, Dearden C, Hinton TJ (2006) The physical properties of the atmosphere in the New Hadley Centre Global Environmental Model (HadGEM1). Part I: model description and global climatology. J Clim 19(7):1274-1301. doi:10.1175/JCLI3636.1

Martin GM, Milton SF, Senior CA, Brooks ME, Ineson S, Reichler T, Kim J (2010) Analysis and reduction of systematic errors through a seamless approach to modeling weather and climate. J Clim 23(22):5933-5957. doi:10.1175/2010JCLI3541.1

Neale R, Slingo J (2003) The Maritime Continent and its role in the global climate: a GCM study. J Clim 16(5):834-848. doi:10. 1175/1520-0442(2003)016<0834:TMCAIR $>2.0 . C O ; 2$

Pope VD, Stratton RA (2002) The processes governing horizontal resolution sensitivity in a climate model. Clim Dyn 19(3-4):211-236. doi:10.1007/s00382-001-0222-8

Qian JH (2008) Why precipitation is mostly concentrated over islands in the Maritime Continent. J Atmos Sci 65(4):1428-1441. doi:10.1175/2007JAS2422.1

Randall D, Wood R, Bony S, Colman R, Fichefet T, Fyfe J, Kattsov V, Pitman A, Shukla J, Srinivasan J, Stouffer R, Sumi A, Taylor K (2007) Climate models and their evaluation. In: Climate change 2007: the physical science basis. Contribution of working group I to the fourth assessment report of the intergovernmental panel on climate change. Cambridge University Press, chap Climate Mo, pp 589-662

Rayner NA, Brohan P, Parker DE, Folland CK, Kennedy JJ, Vanicek M, Ansell TJ, Tett SFB (2006) Improved analyses of changes and uncertainties in sea surface temperature measured in situ since the mid-nineteenth century: the HadSST2 dataset. J Clim 19(3):446-469. doi:10.1175/JCLI3637.1

Ringer MA, Martin GM, Greeves CZ, Hinton TJ, James PM, Pope VD, Scaife AA, Stratton RA, Inness PM, Slingo JM, Yang GY (2006) The physical properties of the atmosphere in the New Hadley Centre Global Environmental Model (HadGEM1). Part II: aspects of variability and regional climate. J Clim 19(7):1302-1326. doi:10.1175/JCLI3713.1

Roberts MJ, Banks H, Gedney N, Gregory J, Hill R, Mullerworth S, Pardaens A, Rickard G, Thorpe R, Wood R (2004) Impact of an eddy-permitting ocean resolution on control and climate change simulations with a global coupled GCM. J Clim 17(1):3-20. doi:10.1175/1520-0442(2004)017<0003:IOAEOR > 2.0.CO;2

Roberts MJ, Clayton A, Demory ME, Donners J, Vidale PL, Norton W, Shaffrey L, Stevens DP, Stevens I, Wood RA, Slingo J (2009) Impact of resolution on the tropical Pacific circulation in a matrix of coupled models. J Clim 22(10):2541-2556. doi:10. 1175/2008JCLI2537.1

Rodwell MJ, Hoskins BJ (1996) Monsoons and the dynamics of deserts. Q J R Meteorol Soc 122(534):1385-1404. doi:10.1002/ qj. 49712253408

Senior CA (1995) The dependence of climate sensitivity on the horizontal resolution of a GCM. J Clim 8(11):2860-2880. doi:10.1175/1520-0442(1995)008<2860:TDOCSO > 2.0.CO;2

Shaffrey LC, Stevens I, Norton WA, Roberts MJ, Vidale PL, Harle JD, Jrrar A, Stevens DP, Woodage MJ, Demory ME, Donners J, Clark DB, Clayton A, Cole JW, Wilson SS, Connolley WM, Davies TM, Iwi AM, Johns TC, King JC, New AL, Slingo JM, Slingo A, Steenman-Clark L, Martin GM (2009) U.K. HiGEM: the New U.K. high-resolution global environment modelmodel description and basic evaluation. J Clim 22(8):1861-1896. doi:10.1175/2008JCLI2508.1

Slingo J, Inness P, Neale R, Woolnough S, Yang Gy (2003) Scale interactions on diurnal to seasonal timescales and their relevance to model systematic errors. Ann Geophys 46(1):139-155. doi:10. 4401/ag-3383

Slingo J, Bates K, Nikiforakis N, Piggott M, Roberts M, Shaffrey L, Stevens I, Vidale PL, Weller H (2009) Developing the nextgeneration climate system models: challenges and achievements. Philos Trans Ser A, Math Phys Eng Sci 367(1890):815-831 doi:10.1098/rsta.2008.0207

Stephenson DB, Chauvin F, Royer JF (1998) Simulation of the Asian summer monsoon and its dependence on model horizontal resolution. J Meteorl Soc Japan 76(2):237-265

Strachan J (2007) Understanding and modelling the climate of the Maritime Continent. Phd thesis, University of Reading

Strachan J, Vidale PL, Hodges K, Roberts M, Demory ME (2012) Investigating global tropical cyclone activity with a hierarchy of AGCMs: the role of model resolution. J Clim. doi:10.1175/JCLID-12-00012.1

Taylor KE, Williamson D, Zwiers F (2000) The sea surface temperature and sea-ice concentration boundary conditions for AMIP II simulations. Technical report 60, PCMDI

Toniazzo T, Mechoso CR, Shaffrey LC, Slingo JM (2009) Upperocean heat budget and ocean eddy transport in the south-east Pacific in a high-resolution coupled model. Clim Dyn 35(78):1309-1329. doi:10.1007/s00382-009-0703-8

Vecchi GA, Soden BJ, Wittenberg AT, Held IM, Leetmaa A, Harrison MJ (2006) Weakening of tropical Pacific atmospheric circulation due to anthropogenic forcing. Nat 441(7089):73-76. doi:10.1038/nature04744

Walters DN, Best MJ, Bushell AC, Copsey D, Edwards JM, Falloon PD, Harris CM, Lock AP, Manners JC, Morcrette CJ, Roberts MJ, Stratton RA, Webster S, Wilkinson JM, Willett MR, Boutle LA, 
Earnshaw PD, Hill PG, MacLachlan C, Martin GM, MoufoumaOkia W, Palmer MD, Petch JC, Rooney GG, Scaife AA, Williams KD (2011) The Met Office Unified Model Global Atmosphere 3.0/3.1 and JULES global land 3.0/3.1 configurations. Geosci Model Dev 4(4):919-941. doi:10.5194/gmd-4-919-2011

Wang B, Lee JY, Kang IS, Shukla J, Kug JS, Kumar A, Schemm J, Luo JJ, Yamagata T, Park CK (2007) How accurately do coupled climate models predict the leading modes of Asian-Australian monsoon interannual variability? Clim Dyn 30(6):605-619. doi:10.1007/s00382-007-0310-5

Williamson DL, Kiehl JT, Hack JJ (1995) Climate sensitivity of the NCAR Community Climate Model (CCM2) to horizontal resolution. Clim Dyn 11(7):377-397. doi:10.1007/BF00209513 